06

\title{
Удельные сопротивления и тензорезистивные характеристики кристаллов твердых растворов системы TIInSe ${ }_{2}-\mathrm{CulnSe}_{2}$
}

\author{
(C) С.Х. Умаров, ${ }^{1}$ И. Нуритдинов, ${ }^{2}$ Ж.Ж. Ашуров, ${ }^{1}$ Ф.К. Халлоков ${ }^{1}$ \\ ${ }^{1}$ Бухарский медицинский институт им. Абу Али ибн Сино, \\ 200118 Бухара, Узбекистан \\ ${ }^{2}$ Институт ядерной фризики АН РУз, \\ 100214 Ташкент, Узбекистан \\ e-mail:Salim_umarov49@mail.ru \\ (Поступило в Редакцию 17 октября 2017 г.)
}

На основании исследования концентрационных зависимостей удельных сопротивлений и коэффициентов тензочувствительности сплавов $\mathrm{Tl}_{(1-x)} \mathrm{Cu}_{x} \mathrm{InSe}_{2}$ в системе TlInSe $2-\mathrm{CuInSe}_{2}$ в концентрационном интервале $x=0-0.1$ установлено, что в области существования твердых растворов $(x=0-0.025)$ исследованные характеристики имеют линейные концентрационные зависимости, которые резко изменяются при переходе границы области существования твердых растворов.

DOI: $10.21883 /$ JTF.2019.02.47073.2514

\section{Введение}

Кристалл $\mathrm{TlInSe}_{2}$ является одним из представителей неполновалентных полупроводниковых соединений, имеющим специфическую кристаллическую структуру, состоящую из двух самостоятельных структурных полиэдров - октаэдров с ионами $\mathrm{Tl}^{+}$и тетраэдров с ионами $\mathrm{In}^{3+}[1-3]$. Элементарная ячейка этих кристаллов содержит две самостоятельные структурные единицы, обеспечивающие для составляющих разноименных катионов одной и той же группы различную координацию, валентное состояние и характер химических связей. Эти особенности являются причиной резкой анизотропии физических свойств полупроводников данного типа. Цепочечное строение и особенность раскалывания их кристаллов на нитевидные и слоистые пластинки с зеркальными гранями является следствием резкой асимметрии химической связи. Эти характеристики, а также возможность введения разновалентных примесей в кристаллическую решетку TIInSe ${ }_{2}$, обусловливает повышенный интерес к исследованиям электронной структуры и свойств кристаллов данного класса.

В работах [4-6] обнаружено, что введение в структуру примеси $\mathrm{Cu}$ приводит к повышению электропроводности, фоточувствительности, увеличению коэффициента тензочувствительности, уменьшению токовых шумов и снижению темнового тока изготовленных на основе кристаллов TIInSe 2 фоторезисторов. Целью настоящей работы является изучение влияния изменения концентрации меди на некоторые электрофизические и тензорезистивные характеристики кристаллов системы $\mathrm{Tl}_{(1-x)} \mathrm{Cu}_{x} \mathrm{InSe}_{2}$ при значениях концентрации $x=0-0.1$.

\section{Методика эксперимента}

Тройные соединения $\mathrm{TlInSe}_{2}$ и сплавы системы $\mathrm{TlInSe}_{2}-\mathrm{CuInSe}_{2}$ были синтезированы усовершенство- ванным методом Бриджмена-Стокбаргера. Исходными материалами для синтеза являлись элементы особой чистоты: таллий Т1-000, медь ОСЧ 11-4, селен ОСЧ 17-4, индий In-000.

Образцы для измерения электрофизических и фотоэлектрических характеристик кристаллов изготовлялись из свежесколотых плоскопараллельных пластинок с эффективной фоточувствительной площадью $0.013-0.054 \mathrm{~cm}^{2}$ и толщиной $0.02-0.19 \mathrm{~cm}$. Контакты наносились наплавлением индия. Размеры исследованных образцов составляли $10 \times 10 \times 0.25 \mathrm{~mm}$. Омические контакты получены точечной сваркой соответствующих проволок конденсаторным разрядом на торцы нагретых в потоке инертного газа образцов на поверхность скола и обеспечивали линейный характер вольт-амперных характеристик (BAX) до напряженностей электрического поля $E=100 \mathrm{~V} / \mathrm{cm}$.

Измерения фототока проводились при немодулированном потоке светового излучения. При изучении стационарной фотопроводимости напряжение в измерительной цепи находилось в пределах линейного участка BAX образцов. Тензочувствительность образцов по направлению [001] измерялась в статическом режиме по методике, приведенной в [7] в температурном интервале $300-575 \mathrm{~K}$.

\section{Результаты и их обсуждение}

При исследовании электрических свойств монокристаллов системы TlInSe $2-\mathrm{CuInSe}_{2}$ и производстве этих материалов, структур и приборов возникает необходимость измерения удельного электрического сопротивления или удельной электрической проводимости полупроводниковых материалов $\mathrm{Tl}_{(1-x)} \mathrm{Cu}_{x} \mathrm{InSe}_{2}$ в виде монокристаллических слитков, образцов различной геометрической формы, пластин, диффузионных, эпитаксиальных и ионно-легированных слоев, составляю- 
Таблица 1. Электрофизические и фотоэлектрические параметры кристаллов $\mathrm{Tl}_{1-x} \mathrm{Cu}_{x} \mathrm{InSe}_{2}$

\begin{tabular}{|c|c|c|c|c|c|}
\hline $\begin{array}{l}\text { Составы } \\
\text { кристаллов } \\
\text { тензодатчи } \\
\text { ков }\end{array}$ & $\begin{array}{c}\text { Номинальные } \\
\text { сопротивления, } \\
\Omega\end{array}$ & $\begin{array}{c}\text { Удельные } \\
\text { сопртивления } \\
\Omega \cdot \mathrm{cm}\end{array}$ & $\begin{array}{c}\text { Световые } \\
\text { коэффициенты } \\
\text { сопротивления } \\
\text { \%/lux }\end{array}$ & $\begin{array}{c}\text { Световые } \\
\text { коэффициенты } \\
\text { чувствительности, } \\
\text { \%/lux }\end{array}$ & $\begin{array}{l}\text { Размеры } \\
\text { образцов, } \\
\mathrm{mm}^{3}\end{array}$ \\
\hline $\mathrm{TlInSe}_{2}$ & $6.87 \cdot 10^{10}$ & $21.26 \cdot 10^{6}$ & $-1.03 \cdot 10^{3}$ & $1.76 \cdot 10^{3}$ & $0.13 \times 0.25 \times 10.5$ \\
\hline $\begin{array}{l}99 \% \mathrm{TlInSe}_{2}- \\
1 \% \mathrm{CuInSe}_{2}\end{array}$ & $4.49 \cdot 10^{10}$ & $13.7 \cdot 10^{6}$ & $-4.01 \cdot 10^{3}$ & $4.36 \cdot 10^{3}$ & $0.13 \times 0.23 \times 9.8$ \\
\hline $\begin{array}{l}98 \% \mathrm{TlInSe}_{2}- \\
2 \% \mathrm{CuInSe}_{2}\end{array}$ & $1.32 \cdot 10^{10}$ & $6.4 \cdot 10^{6}$ & $-7.21 \cdot 10^{3}$ & $7.8 \cdot 10^{3}$ & $0.16 \times 0.24 \times 7.9$ \\
\hline $\begin{array}{l}97 \% \mathrm{TlInSe}_{2}- \\
3 \% \mathrm{CuInSe}_{2}\end{array}$ & $4.3 \cdot 10^{9}$ & $2.5 \cdot 10^{6}$ & $-3.56 \cdot 10^{3}$ & $1.20 \cdot 10^{3}$ & $0.19 \times 0.26 \times 8.5$ \\
\hline $\begin{array}{l}\text { 95\% } \mathrm{TlInSe}_{2}- \\
5 \% \mathrm{CuInSe}_{2}\end{array}$ & $2.86 \cdot 10^{9}$ & $1.6 \cdot 10^{6}$ & $-4.25 \cdot 10^{3}$ & $1.42 \cdot 10^{3}$ & $0.14 \times 0.24 \times 6$ \\
\hline $\begin{array}{l}90 \% \mathrm{TlInSe}_{2}- \\
10 \% \mathrm{CuInSe}_{2}\end{array}$ & $2.64 \cdot 10^{9}$ & $1.31 \cdot 10^{6}$ & - & - & $0.14 \times 0.23 \times 6.5$ \\
\hline
\end{tabular}

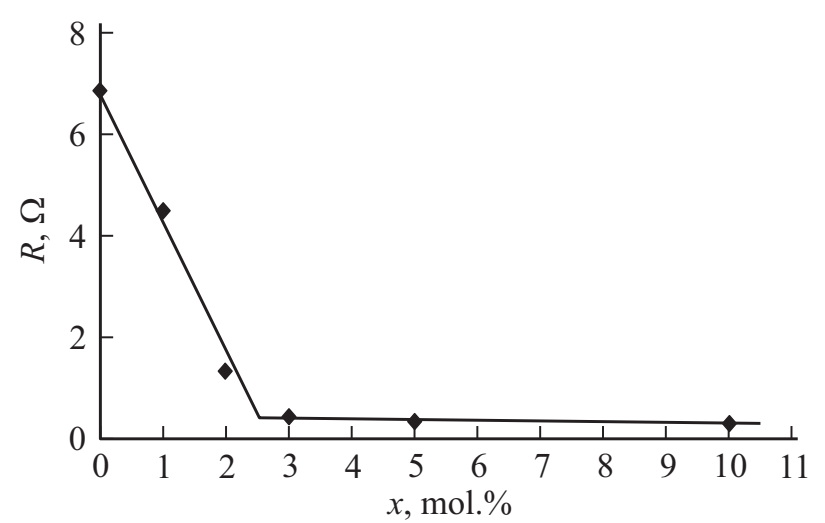

Рис. 1. Зависимость номинального сопротивления сплавов $\mathrm{Tl}_{1-x} \mathrm{Cu}_{x} \mathrm{InSe}_{2} R$ от концентрации $\mathrm{Cu}$.

щих часть полупроводниковых структур. Данные по удельному сопротивлению необходимы для установления важных параметров полупроводникового материала на основе теоретических расчетов или дополнительных экспериментальных данных.

Выбор метода измерения осуществляют с учетом требований к получению информации об особенностях исследуемого материала, возможности изготовления электрических контактов, геометрической формы образца, метрологических характеристик метода измерения. В идеальном случае измерения характеристик монокристаллов твердых растворов $\mathrm{Tl}_{(1-x)} \mathrm{Cu}_{x} \mathrm{InSe}_{2}$ не должны приводить к разрушению образца и не должны требовать его специальной обработки.

В табл. 1 приведены результаты измерений электрофизических и фотоэлектрических свойств сплавов системы $\mathrm{Tl}_{(1-x)} \mathrm{Cu}_{x} \mathrm{InSe}_{2}$ в интервале концентрации меди $x=0-0.1$, откуда видно, что номинальное сопротивле- ние сплавов $R$ и удельное сопротивление $\rho$ от концентрации меди $x$ в интервалах $x=0-0.025$ и $0.025-0.1$ линейно уменьшаются, образуя характерный излом при $x=0.025$ (рис. 1 и 2). Именно при концентрации меди $x=0.025$ наблюдается скачок коэффициентов светового сопротивления и световой чувствительности легированных образцов (табл. 1, рис. 3 и 4).

В концентрационных зависимостях среднего значения коэффициента тензочувствительности $K$ при сжатии и растяжении происходит излом или скачок также при концентрации меди $x=0.025$ (рис. 5 и табл. 2).

Авторами [8] на основании дифференциального термического и рентгенофазового анализов, а также измерений удельной электропроводности и плотности сплавов было установлено, что в системе TlInSe $2-\mathrm{CuInSe}{ }_{2}$ образуются ограниченные твердые растворы, составляющие при комнатной температуре концентрации до $2.5 \mathrm{~mol} . \%$ со стороны TlInSe 2 и $1.5 \mathrm{~mol} \%$ со стороны $\mathrm{CuInSe}_{2}$. На рентгенограммах всех исследованных сплавов проявились только линии TlInSe 2 или $\mathrm{CuInSe}_{2}$. В интервале

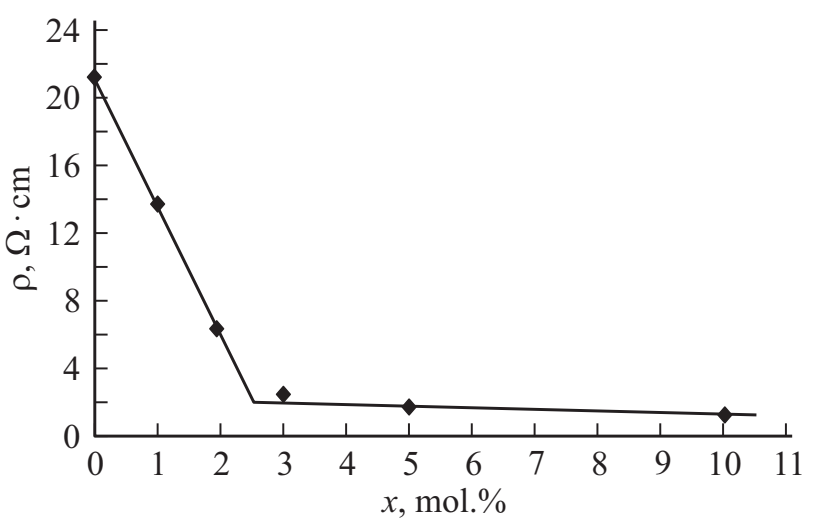

Рис. 2. Зависимость удельного сопротивления сплавов $\mathrm{Tl}_{1-x} \mathrm{Cu}_{x} \mathrm{InSe}_{2}$ от концентрации $\mathrm{Cu}$. 
Таблица 2. Средние значения коэффициента тензочувствительности $\left(K_{\mathrm{aver}}\right)$ сплавов $\mathrm{Tl}_{1-x} \mathrm{Cu}_{x} \mathrm{InSe}_{2}$ вдоль оси [001]

\begin{tabular}{l|c|c}
\hline $\begin{array}{l}\text { Составы сплавов } \\
\text { тензодатчика }\end{array}$ & $\begin{array}{c}K_{\text {aver }}, \\
\text { при сжатии }\end{array}$ & $\begin{array}{c}K_{\text {aver }}, \\
\text { при растяжении }\end{array}$ \\
\hline TlInSe $_{2}$ & 464 & 464 \\
$99 \% \mathrm{TlInSe}_{2}-1 \% \mathrm{CuInSe}_{2}$ & 280 & 862 \\
$98 \% \mathrm{TIInSe}_{2}-2 \% \mathrm{CuInSe}_{2}$ & 162 & 1115 \\
$97 \% \mathrm{TlInSe}_{2}-3 \% \mathrm{CuInSe}_{2}$ & 122 & 341 \\
$95 \% \mathrm{TlInSe}_{2}-5 \% \mathrm{CuInSe}_{2}$ & 149 & 411 \\
$90 \% \mathrm{TlInSe}_{2}-10 \% \mathrm{CuInSe}_{2}$ & 300 & 697
\end{tabular}

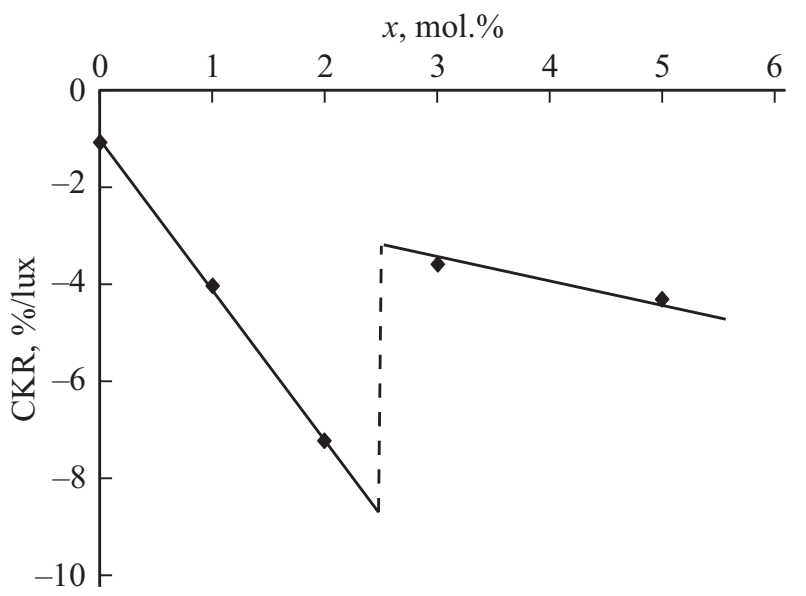

Рис. 3. Зависимость светового сопротивления кристаллов $\mathrm{Tl}_{1-x} \mathrm{Cu}_{x} \mathrm{InSe}_{2}$ от концентрации $\mathrm{Cu}$.

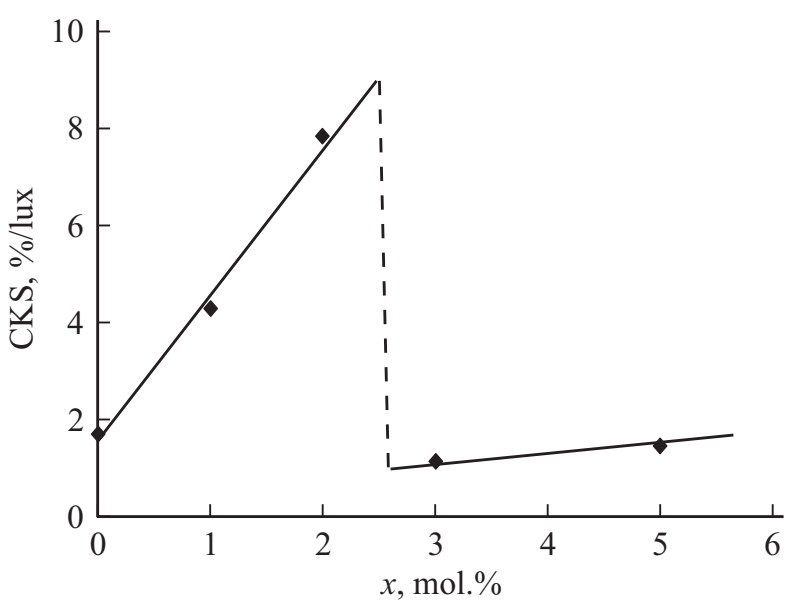

Рис. 4. Зависимость коэффициента световой чувствительности кристаллов $\mathrm{Tl}_{1-x} \mathrm{Cu}_{x} \mathrm{InSe}_{2}$ от концентрации $\mathrm{Cu}$.

концентрации меди $x=0-0.025$ наблюдаются линии, характерные только для кристаллов $\mathrm{Tl} \operatorname{InSe} \mathrm{S}_{2}$, а в интервале концентрации 0-0.985 - только для кристаллов $\mathrm{CuInSe}_{2}$. В пределах концентрации меди в интервале $x=0.025-0.985$ обнаружены линии, характерные для обоих соединенй, т.е. в данном концентрационном интервале сплавы является двухфазными - они представляют собой смесь кристаллов $\mathrm{TlInSe}_{2}$ и $\mathrm{CuInSe}_{2}$ в

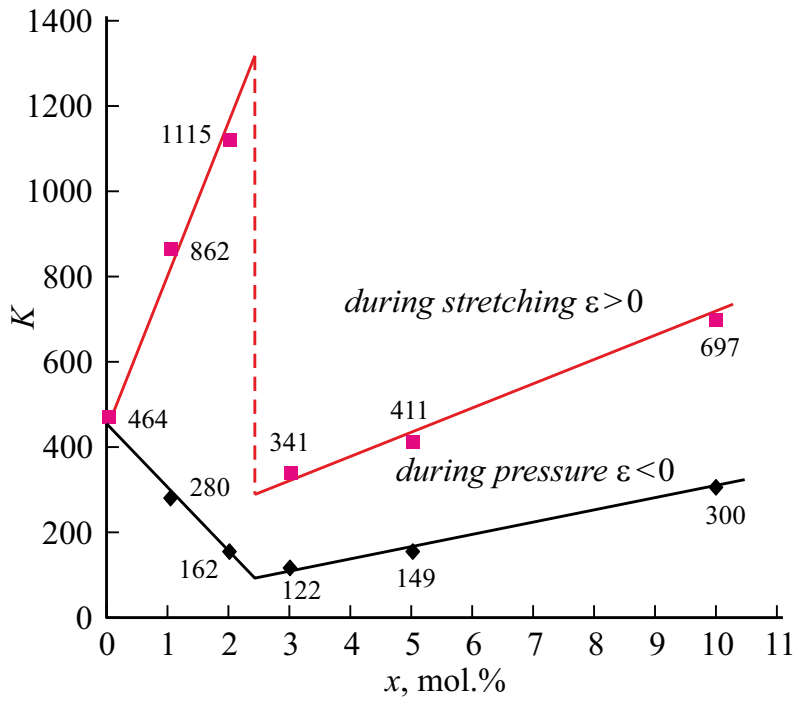

Рис. 5. Зависимость среднего значения коэффициента тензочувствительности сплава $\mathrm{Tl}_{1-x} \mathrm{Cu}_{x} \mathrm{InSe}_{2}$ вдоль оси [001] от концентрации $\mathrm{Cu}$.

различных соотношениях. Установлено, что в сплавах системы $\mathrm{Tl}_{(1-x)} \mathrm{Cu}_{x} \mathrm{InSe}_{2}$ в интервале $x=0-0.1$ с повышением концентрации меди увеличивается удельная электропроводность сплавов и уменьшаются параметры тетрагональных ячеек, образуя характерный излом при концентрации $x=0.025$, что объясняется фазовым переходом в системе при этой концентрации. Примечательно то, что обнаруженные нами изломы или скачки в концентрационных зависимостях исследованных физических свойств в системе $\mathrm{Tl}_{(1-x)} \mathrm{Cu}_{x} \mathrm{InSe}_{2}$ происходит именно при значении $x=0.025$. Все это показывает, что в области существования твердых растворов многие свойства системы $\mathrm{Tl}_{(1-x)} \mathrm{Cu}_{x} \mathrm{InSe}_{2}$, в том числе номинальное и удельное сопротивления, коэффициенты светового сопротивления, световой чувствительности и тензочувствительности при фиксированных температуpax имеют линейные концентрационные зависимости, которые претерпевают резкое изменение при переходе границы существования твердых растворов.

\section{Заключение}

Исследованы номинальные и удельные сопротивления, а также коэффициенты светового сопротивления, световой чувствительности и тензочувствительности синтезированных сплавов $\mathrm{Tl}_{(1-x)} \mathrm{Cu}_{x} \mathrm{InSe}_{2}$ в системе TIInSe $\mathrm{Se}_{2}-\mathrm{CuInSe} \mathrm{I}_{2}$ в концентрационном интервале $x=0-0.1$. В области существования твердых растворов (в пределах $x=0-0.025)$ все исследованные характеристики имеют линейные концентрационные зависимости, которые резко изменяются при переходе границы области существования твердых растворов, что обусловлено концентрационными фазовыми изменениями в системе $\mathrm{TlInSe}_{2}-\mathrm{CuInSe}$. 


\section{Список литературы}

[1] Guseeinov G.D., Ramazanzae A.M., Kerimova E.M. et al. // Phys. Stat. Sol. 1969. Vol. 33. N 1. P. 33.

[2] Guseeinov G.D., Abdullaev G.B., Bidzinova S.M. et al. // Phys. Lett. A. 1970. Vol. 33. N 7. P. 412-422.

[3] Гусейнов Г.Д. Поиск и физические исследования новых полупроводниковых аналогов. Автореф. канд. дис. Вильнюс: Вильнюсский гос. ун-т, 1972. 60 с.

[4] Нуритдинов И., Умаров С.Х., Рустамов В.Д. // Перспективные материалы. 2003. № 1. С. 46-48.

[5] Аиуров Ж.Д., Нуритдинов И., Умаров С.Х. // Узбекский физич. журнал. 2008. Т. 10. № 2. С. 132-141.

[6] Ащуров Ж.Д., Нуритдинов И., Умаров С.Х. // Перспективные материалы. 2011. № 1. С. 11-14.

[7] Умаров С.Х., Рустамов В.Д., Нуритдинов И. // Перспективные материалы. 2002. № 6. С. 41-42.

[8] Георгобеани А.Н., Матиев А.Х., Хамхоев Б.М., Евлоев А.M. // Неорганич. материалы. 2005. Т. 41. № 5. C. 281-285. 